\title{
Impacto Ambiental Sobre a Saúde Humana Devido à Exposição aos Agrotóxicos
}

\author{
Environmental Impact on Human Health Due to Pesticide Exposure
}

Bruno Pereira do Nascimento ${ }^{\text {; }}$, Renata Cristina Giroto Ferreira da Silva ${ }^{a}$; Alexsander Pippus Ferreira ${ }^{\text {a }}$ Evanilda Custodio da Silva a ; Jardes Arquimedes de Figueiredo Junior ${ }^{a}$; Leandro Lourenco de Oliveira Dias ${ }^{\text {a }}$; Paulo Henrique Nascimento Campos; ; Ageo Mário Cândido da Silva*a

${ }^{a}$ Universidade de Cuiabá, Programa de Pós-Graduação Stricto Sensu em Ambiente e Saúde. MT, Brasil.

*E-mail: ageoms@gmail.com

\begin{abstract}
Resumo
É grande a problemática envolta na utilização dos agrotóxicos no Brasil e no Mundo, os danos cumulativos para a saúde humana é remontada em diversas pesquisas, que elucidam diversas alterações sistemáticas, que acometem as populações expostas. Sendo necessária a discussão e a implementação de políticas públicas efetivas na saúde do trabalhador, a fim de prevenir o risco do desenvolvimento de comorbidades associadas aos agrotóxicos. Objetivo: analisar a exposição materna aos agrotóxicos e a ocorrência de prematuridade no Estado de Mato Grosso no período de 2008 a 2018. Metodologia: trata-se de um estudo quantitativo, ecológico, abrangendo o período de 2011 a 2017 , conduzido em municípios do Estado de Mato Grosso. Os óbitos fetais e nascidos vivos com malformação foram obtidos através do Sistema de Informações de Nascidos Vivos (SINASC). E as estatísticas da população daquele determinado município foram filtrados pelo Instituto Brasileiro de Geografia e Estatística (IBGE).
\end{abstract}

Palavras-chave: Agrotóxicos. Prematuridade. Cuidado Pré-Natal.

\begin{abstract}
The problem involved in the use of pesticides in Brazil and in the world is great, the cumulative damage to human health is traced in several studies that elucidate several systematic changes that affect the exposed populations. It is necessary to discuss and implement effective public policies on the worker health, in order to prevent the risk of developing comorbidities associated with pesticides. Objective: To analyze maternal exposure to pesticides and the occurrence of prematurity in the state of Mato Grosso from 2008 to 2018. Methodology: This is a quantitative, ecological study, covering the period from 2011 to 2017, conducted in municipalities in the State of Mato Grosso. Fetal deaths and live births with malformation were obtained through the Live Birth Information System (SINASC). And the population statistics for that particular municipality were filtered by the Brazilian Institute of Geography and Statistics (IBGE).
\end{abstract}

Keywords: Pesticides. Prematurity. Prenatal Care.

\section{Introdução}

A partir da metade do século XX, a revolução verde, deflagrada pelos grandes produtores agrícolas, trazia como argumento que a produção de alimentos, em grande escala, poderia exterminar a fome no Mundo, gerando emprego e comida para as populações desfavorecidas socialmente (ANDRADE; GANIMI, 2007).

Nesse cenário, o Brasil adotou este modelo em meados de 1960-1970, durante a Ditadura Militar. Esta medida, por um lado, permitiu que o país desenvolvesse tecnologia própria em Universidades, Centros de Pesquisa, Agências governamentais e Instituições privadas, se transformando em um dos grandes recordistas de produção e de exportação no cenário do agronegócio global (PORTO; SOARES, 2012). Contudo, foram observadas intensas alterações no processo tradicional de trabalho agrícola, assim como em seus impactos sobre o ambiente e a saúde humana. Junto com essas mudanças veio o grande uso extensivo de agentes químicos, sendo disponibilizadas para o controle de doenças, aumento da produtividade e proteção contra insetos e outras pragas (TYBUSH; MARTINS, 2016), contribuindo para a utilização desregrada e desenfreada, de compostos químicos em excesso no manejo do solo, sendo a gênese de vários problemas de ordem pública, sanitária e ambiental atualmente (MATOS, 2010).

Há uma grande discussão em relação à nomenclatura correta a ser utilizada para se referir a esses produtos, sendo utilizados os seguintes termos: defensivos agrícolas, agrotóxicos, pesticidas, praguicidas, remédios de planta, veneno, entre outros, essas são algumas das inúmeras denominações para o grupo de substâncias químicas utilizadas no controle de pragas e doenças de plantas, tão grande como a lista dos termos são os efeitos nocivos à saúde humana (PERES et al., 2003).

O projeto de Lei do Senado, no 680 de 2015, prevê atualmente a alteração do termo agrotóxico para fitossanitário, explicando que a palavra/termo é utilizada no Mercosul, desse modo melhoraria o ambiente de negócios para os produtores rurais no Brasil, associando ao termo usual uma conotação negativa. Os termos "pesticidas" e "praguicidas" também são 
utilizados, mascarando o aspecto da saúde humana e ambiental, denotando apenas o aspecto biológico (BEDOR, 2008).

No arcabouço da legislação brasileira, as discussões acerca dos agrotóxicos (denominação constante na legislação atualmente) iniciaram com a Constituição de 1988, que adotava a nomenclatura de defensivos agrícolas, denominação que, pelo seu próprio significado, excluía todos os agentes utilizados nas campanhas sanitárias urbanas, escondendo a ideia de que as plantas são totalmente vulneráveis às pragas e doenças, mascarando os efeitos prejudiciais à saúde humana (PERES et al., 2003).

Com a aprovação das Normas Regulamentadoras (NRs), em 1978, que concernem a respeito da Segurança e Medicina do Trabalho. A Norma Regulamentadora Rural (NRR) n5, revogada pela Portaria 191 de 15 de abril de 2008, que trata da utilização de produtos químicos no trabalho rural humano, posteriormente alterada pelo processo da Constituição Federal de 1988, aprovou a Lei Federal n ${ }^{\text {0 }} 7.802$, de 11 de julho de 1989, definindo o termo agrotóxico (PERES et al., 2003).

\section{Desenvolvimento}

Com o advento da Segunda Guerra Mundial, empresas de produtos químicos responsáveis por abastecer a indústria bélica norte-americana começaram a produzir e estimular a utilização de agrotóxicos, como: herbicidas, fungicidas, inseticidas e fertilizantes químicos, juntamente com o emprego de novas tecnologias (maquinário) no campo (TYBUSH; MARTINS, 2016).

Os agrotóxicos compreendem um grupo heterogêneo de agentes químicos desenvolvidos para o controle de uma gama de pragas nas plantações. Esses são classificados de acordo com o tipo de praga a ser combatida, sendo: inseticidas, herbicidas ou fungicidas (BOLOGNESI, 2003).

O Quadro 1 apresenta a classificação dos principais agrotóxicos usados, quanto a sua ação em um determinado tipo de organismo e ao grupo químico ao qual pertence.

Quadro 1 - Classificação dos agrotóxicos de acordo com o organismo alvo e a estrutura química

\begin{tabular}{|c|c|c|}
\hline $\begin{array}{c}\text { Tipo de } \\
\text { Agrotóxico }\end{array}$ & Alvo & Grupo Químico \\
\hline Inseticidas & $\begin{array}{l}\text { Possuem ações de } \\
\text { combate a insetos, } \\
\text { larvas e formigas }\end{array}$ & $\begin{array}{l}\text { Organoclorados } \\
\text { Organofosforados } \\
\text { Carbamatos } \\
\text { Piretroides }\end{array}$ \\
\hline Fungicidas & Combatem fungos & $\begin{array}{l}\text { Etileno-bis-ditiocarbanatos } \\
\text { Dimetilditiocarbamatos } \\
\text { Nitrogenados Heterocíclicos } \\
\text { Substitutos do Benzeno } \\
\text { Benzimidazóis } \\
\text { Ftalimidas }\end{array}$ \\
\hline Herbicidas & $\begin{array}{c}\text { Combatem ervas } \\
\text { daninhas }\end{array}$ & $\begin{array}{l}\text { Derivados da Glicina } \\
\text { (Glifosato) } \\
\text { Bipiridilos não seletivos } \\
\text { Cloroxenofiacéticos } \\
\text { Triazinas } \\
\text { Dinitrofenóis e dinitrocresóis }\end{array}$ \\
\hline
\end{tabular}

Fonte: Adaptado de Santos (2013).
Os inseticidas são produtos à base de substâncias químicas ou agentes biológicos, que possuem ação direta ou indireta, provocando a morte de insetos, sendo o principal agente responsável por intoxicações (IBAMA, 2009; SIQUEIRA, 2008). O termo fungicida tem por significado matar o fungo, sendo que todo agente físico, químico ou biológico prejudicial aos fungos pode ser classificado como fungicida (IBAMA, 2009).

Os herbicidas são substâncias químicas que têm ação de reduzir ou eliminar plantas infestantes (ervas daninhas), responsáveis por perdas nas culturas. No Brasil se observa um aumento crescente no consumo de agrotóxicos, principalmente a classe dos herbicidas, sendo a principal razão, a expansão agrícola, sendo descrito em relatórios do sistema de Comercialização de Agrotóxicos do Ibama como os agrotóxicos mais comercializados no Brasil (IBAMA, 2009; SIQUEIRA, 2008).

A grande maioria destes agentes químicos é composta por substâncias nocivas ao ser humano, como, por exemplo, hidrocarbonetos aromáticos, organofosforados, carbamatos e organoclorados, entre outros, possuindo a habilidade de se depositar no meio ambiente por vários anos. É importante destacar que, juntamente, com os compostos químicos, que empregam os agrotóxicos, fazem parte da sua composição veículos de contaminação, liberados nas reações químicas durante a sua síntese. Como o benzeno, elemento já relatado como mielotóxico e carcinogênico (IARC, 2008).

São divididos de acordo com a sua classe toxicológica, conforme elucidado no (Quadro 2), ou seja, pela capacidade que possuem de provocar a morte de metade de uma população expostos à determinada concentração do composto. Esta dose, chamada DL 50 (dose letal) é a dose necessária de uma dada substância para matar $50 \%$ de uma população em teste. A determinação é realizada expondo cobaias a variadas doses da substância até ser apontada aquela que mata apenas metade da população testada. A DL50 é, frequentemente, usada como um indicador da toxicidade aguda de uma substância (FERREIRA FILHO, 2013).

Quadro 2 - Classificação dos Agrotóxicos

\begin{tabular}{|c|c|c|c|}
\hline $\begin{array}{c}\text { Classe } \\
\text { Toxicológica }\end{array}$ & Grupo & DL 50 & $\begin{array}{c}\text { Indicação do } \\
\text { Rótulo }\end{array}$ \\
\hline I & $\begin{array}{c}\text { Altamente } \\
\text { Perigo }\end{array}$ & $<0,05 \mathrm{~g} / \mathrm{kg}$ & $\begin{array}{c}\text { Vermelho } \\
\text { vivo }\end{array}$ \\
\hline II & $\begin{array}{c}\text { Muito } \\
\text { Perigoso }\end{array}$ & $\begin{array}{c}0,05 \mathrm{a} 0,5 \mathrm{~g} / \\
\mathrm{kg}\end{array}$ & $\begin{array}{c}\text { Amarelo } \\
\text { intenso }\end{array}$ \\
\hline III & Perigoso & $0,5 \mathrm{a} 5 \mathrm{~g} / \mathrm{kg}$ & Azul intenso \\
\hline IV & $\begin{array}{c}\text { Pouco } \\
\text { Perigoso }\end{array}$ & $>5 \mathrm{~g} / \mathrm{kg}$ & Verde intenso \\
\hline
\end{tabular}

Fonte: Adaptado da Portaria Normativa Ibama $\mathrm{n}^{\circ} 84$, de 15 de outubro de 1996; Ageitec.

A classificação acima apresentada também está relacionada à ação e ao grupo químico. 


\subsection{Exposição aos agrotóxicos, danos à saúde e ao ambiente}

A Organização Mundial da Saúde (OMS) estima que, a cada ano, em média 3 a 5 milhões de pessoas são contaminadas por agrotóxicos em todo o Mundo, esse número pode chegar a 25 milhões de trabalhadores rurais. No entanto, independentemente do número de indivíduos acometidos, é inegável a seriedade dos problemas, especialmente, nos países em desenvolvimento, que são responsáveis por aproximadamente $20 \%$ do consumo mundial dos agrotóxicos (PERES et al., 2003).

A exposição do indivíduo aos agrotóxicos vai desde a exposição ocupacional pelo contato direto e/ou indireto, dependendo de sua ocupação, bem como ambiental pela contaminação do ar, solo, alimentos, água (ABRASCO, 2012).

A inclusão destas inovações como o uso de agrotóxicos de modo impróprio e indiscriminado acarretou efeitos diretos e danosos sobre o ambiente e a saúde humana, a exposição a estas substâncias são um dos principais problemas de saúde pública (SANTOS, 2013).

Os dados de intoxicação humana e contaminação ambiental provocados pelo uso intensivo e generalizado de agrotóxicos são alarmantes, o uso seguro apresentado pelas indústrias pode mascarar tamanho perigo de seus produtos aos seres humanos (LONDRES, 2012).

Em função de sua toxicidade intrínseca, os agrotóxicos produzem efeitos lesivos à saúde humana, que variam de acordo com o princípio ativo do composto químico, a dose absorvida, a forma de exposição e as características individuais em que o sujeito é exposto, ocasionando no indivíduo intoxicações que podem ser agudas, subagudas/sobreagudas e crônicas (WHO, 2010).

As intoxicações agudas por agrotóxicos são as mais conhecidas e afetam, principalmente, as pessoas expostas em seu ambiente de trabalho (exposição ocupacional). Trazem efeitos como irritação da pele e olhos, coceira, cólicas, vômitos, diarreias, espasmos, dificuldades respiratórias, convulsões e morte (CASSAL et al., 2014; LONDRES, 2012).

Quanto à intoxicação aguda, os sintomas são percebidos logo após o contato com o composto químico, causada geralmente em decorrência de exposições por curto período, porém com concentrações muito elevadas, geralmente, os casos que são notificados são basicamente desse tipo. Intoxicação subaguda/sobreaguda ocorre quando a exposição é moderada ou pequena a produtos alta ou medianamente tóxicos. Os efeitos emergem em alguns dias ou semanas. As manifestações clínicas podem incluir cefaleia, fraqueza, malestar, dor de estômago, sonolência, etc. (LONDRES, 2012).

Já as intoxicações crônicas podem afetar toda a população, pois são decorrentes da exposição múltipla aos agrotóxicos, geralmente, em doses baixas. Os efeitos adversos decorrentes da exposição crônica aos agrotóxicos podem aparecer muito tempo após a exposição, dificultando a correlação com o agente (LONDRES, 2012).
Entre um conjunto de doenças investigadas e relacionadas às exposições crônicas podem ser destacados o câncer e os distúrbios neurodegenerativos como, por exemplo, a doença de Alzheimer, esclerose múltipla, e a doença de Parkinson (SANTOS, 2013).

Os inseticidas organofosforados e carbamatos exercem suas ações biológicas, principalmente, por inibição das enzimas denominadas esterases, em especial, da acetilcolinesterase (AChE), que tem a ação de degradar o neurotransmissor acetilcolina (ACh). Com a AChE inibida, há acúmulo de $\mathrm{ACh}$ nos receptores muscarínicos, nicotínicos e no Sistema Nervoso Central (RELATÓRIO DE INTOXICAÇÕES AGUDAS POR AGROTÓXICOS, 2018).

A associação entre exposição a pesticidas e a doença de Parkinson vem sendo remontada em estudos recentes como o realizado por Wang et al. (2014), em que se utilizou uma ferramenta de avaliação de exposição baseada no sistema de informações geográficas (GIS) para estimar a exposição ambiental a 36 organofosforados comumente usados de 19741999, os autores encontraram que a exposição ambiental a cada organofosforados avaliado separadamente aumentou o risco de desenvolver DP.

De acordo com o Protocolo de Avaliação de Intoxicações Crônicas por Agrotóxicos (Secretaria de Estado e Saúde do Paraná, 2013), as patologias relacionadas à intoxicação crônica por agrotóxicos são:

Neoplasias, como mieloma múltiplo e leucemias; anemia aplástica; transtornos mentais, como alterações cognitivas e episódios depressivos; doenças do sistema nervoso como distúrbios do movimento, polineuropatias e encefalopatia tóxica; oculares, como neurite óptica e distúrbios da visão e ainda auditivas, circulatórias, respiratórias, digestivas e dermatológicas.

Além das patologias apresentadas, estudos recentes apresentam uma relação entre a exposição direta aos agrotóxicos e o alto índice de suicídios em trabalhadores rurais. As substâncias podem afetar o sistema nervoso central, causando transtornos como ansiedade, irritabilidade, insônia ou sono conturbado e depressão, podendo levar o indivíduo ao suicídio (LONDRES, 2012; SANTOS, 2013).

Um dos maiores perigos representados pelos agrotóxicos diz respeito aos efeitos que esses podem provocar na saúde das pessoas, principalmente, daquelas que no campo ou na indústria ficam expostas ao contato direto com os produtos (LONDRES, 2012).

\subsection{Registros e dados de notificação de agrotóxico no Brasil}

O registro de agrotóxicos no Brasil é realizado pelo Ministério da Agricultura, porém a avaliação de risco à saúde humana é feita pela Agência Nacional de Vigilância Sanitária (ANVISA). Os ingredientes ativos de agrotóxicos com uso autorizado no país e os Limites Máximos de Resíduos (LMR) permitidos são publicados pela Agência em documentos chamados Monografias Autorizadas (ANVISA, 2016). 
Quanto ao registro dos dados de intoxicação por agrotóxicos, no Brasil, o mesmo se estabelece através do Sistema Nacional de Informações Tóxico-Farmacológica (SINITOX) (vinculado à FIOCRUZ e que tem por objetivo prestar orientação aos profissionais de saúde com relação às condutas clínicas em casos de intoxicação e, também, orientar a população em relação aos primeiros socorros e medidas de prevenção) e o Sistema de Informação de Agravos de Notificação (SINAN), vinculado diretamente ao Ministério da Saúde, que visa realizar a notificação deste agravo (intoxicação por agrotóxicos) e de outros (BOCHNER, 2007).

Em 2010, o Ministério da Saúde com o intuito de obter um maior número de informações estabeleceu a obrigatoriedade da notificação das intoxicações por agrotóxicos, através do SINAN, em toda a rede pública de saúde. O referido registro sobre intoxicações também pode ser obtido por outros diferentes sistemas como a Comunicação de Acidente de Trabalho (CAT), Sistema de Informações Hospitalares (SIH/ SUS) e Sistema de Informação sobre Mortalidade (SIM). Faria et al. (2009) enfatizam que as discrepâncias nos dados obtidos entre os diferentes sistemas dificultam as análises, sugerindo a integração desses bancos de dados. O autor ainda destaca a descaracterização do receituário agronômico e a importância de se criar um sistema de informações fidedigno sobre o consumo de agrotóxicos.

De acordo com Trabalho Técnico realizado pelo Sindicato Nacional das Empresas de Aviação Agrícola (SINDAG), no Brasil, no ano de 2014, foram notificados 582 casos de intoxicações.

Em 2013, a incidência de intoxicações exógenas por agrotóxicos, no Brasil, foi de 6,23 casos por 100 mil habitantes. No período de 2007 a 2014, houve um aumento de $87 \%$ dos casos notificados, sendo que o total acumulado no período alcançou 68.873 casos. Entre os Estados, que mais notificaram casos de intoxicação exógena por agrotóxicos, no período de 2007 a 2014, tem São Paulo com 12.562 casos, Paraná 10.967, Minas Gerais 10.625 e Pernambuco 5.734, finalizando com o Acre, com apenas 1 caso, sendo o Estado, que menos notificou (BRASIL, 2016).

O Estado do Mato Grosso é considerado um dos grandes polos de produção agropecuária do Brasil, e a incidência de intoxicações por agrotóxicos no Estado apresentou várias oscilações. Houve aumento da incidência até o ano de 2010, voltando a crescer em 2013, o que pode refletir o trabalho da vigilância na sensibilização de gestores e profissionais de saúde para melhoria dos processos de detecção e notificação dos casos (BRASIL, 2016).

Para garantir a contínua identificação e notificação dos casos, bem como as estratégias de prevenção e de assistência, é imprescindível a organização e o fortalecimento das ações de Vigilância em Saúde Ambiental, no âmbito dos Estados e dos municípios. Trabalhando de forma intersetorial, investir em capacitações junto aos profissionais de saúde, que estão envoltos diretamente no atendimento aos casos de intoxicação e manipulam as fichas de notificação, além de estabelecer protocolos de atendimento e, por fim, aprimorar os mecanismos e os fluxos de registro e análise das informações (ALBUQUERQUE et al., 2015).

No Brasil, os profissionais da área da saúde apresentam dificuldade para diagnosticar, registrar e até referenciar um indivíduo intoxicado por agrotóxico. Observa-se que o número de notificações é muito menor que o número legítimo (LONDRES, 2012).

Este padrão de desenvolvimento traz consigo impactos sociais e ambientais, que se reproduzem agudamente e repercutem em longo prazo, os quais são custeados por toda a sociedade através de gastos públicos com recuperação de áreas contaminadas, prevenção, diagnóstico e tratamento de intoxicações agudas e crônicas, afastamentos e aposentadorias por invalidez de trabalhadores rurais e até mortes, perfazendo a ausência de custos, que diretamente estão associados às indústrias químicas (FRIEDRICH; ABRASCO, 2013).

Quando se fala em agrotóxicos, a primeira correlação feita é com seu emprego na agricultura. Entretanto, tem sido aumentada a utilização desses compostos também nas áreas urbanas, como, por exemplo, os inseticidas domésticos que são adquiridos em supermercados, além dos que são utilizados pela saúde pública para o controle de vetores (CÂMARA; AUGUSTO, 2005). A gama de princípios ativos de agrotóxicos é vasta, sendo referidos, aproximadamente, 600 princípios ativos de agrotóxicos e 50 mil formulações comerciais, utilizadas principalmente no combate de doenças, na agricultura e nas áreas urbanas para controle sanitário (TEIXEIRA, 2000).

Por mais que a prática da agricultura seja perpetrada pela humanidade há mais de dez mil anos, a prática de uso intenso de agrotóxicos para o controle de pragas e doenças, que acometem a lavoura teve início há pouco mais de meio século, após as grandes guerras mundiais, as indústrias químicas encontram na agricultura um novo mercado para seus produtos (LONDRES, 2012).

O Governo brasileiro impulsionou a atualização agrícola para o aumento da produtividade, criou-se o Sistema Nacional de Crédito Rural, que subsidiou a entrada dos agrotóxicos através da obrigatoriedade embutida no percentual fixo de gasto com tais substâncias, quando era solicitado o empréstimo para a aquisição de máquinas, e outros componentes do processo produtivo (ANDRADE; GANIMI, 2007).

A partir de 2008, o Brasil começou a liderar o ranking de maior consumidor de agrotóxicos do Mundo. Os impactos na saúde pública são vastos, atingem diversos territórios e envolvem diferentes grupos populacionais, como trabalhadores em diversos ramos de atividades, moradores do entorno de fábricas e fazendas, além de todos que consumem diretamente os alimentos contaminados. Esses impactos estão relacionados com o modelo de produção e desenvolvimento adotado pelo país, que visa a exportação (CARNEIRO, 2015).

A modernização do campo, nesta lógica, foi direcionada 
para a formação de complexos agroindustriais para exportação de monoculturas em larga escala coexistindo com uma grande parcela de pequenas propriedades familiares, que não possuíam meios para se adequar a tal tecnologia. Além disso, a difusão da superioridade tecnológica e seus progressos, em detrimento do conhecimento tradicional exerceram um processo de assujeitamento aos novos padrões vigentes (SANTOS, 2013).

Em 2014, a Associação Brasileira da Indústria Química (ABIQUIM) anunciou o aumento de $13 \%$ nas vendas de agrotóxicos no Brasil, com um faturamento líquido de US\$ 12,2 bilhões (R\$ 25 bilhões), contra US\$11,5 bilhões ( $\mathrm{R} \$ 22$ bilhões) em 2013, segundo dados aportados pelo Sindicato Nacional da Indústria de Produtos para Defesa Vegetal (SINDIVEG) (BRASIL, 2016).

De acordo com Rossi (2015), nos últimos dez anos, o mercado mundial apresentou um crescimento na utilização de agrotóxicos, atingindo cerca de 93\%, enquanto no Brasil, o crescimento foi alarmante com níveis de $190 \%$.

Aguiar et al. (2008) verificaram a associação entre a exposição aos fatores ambientais (pesticidas, herbicidas entre outros) e a doença de Parkinson de Início Precoce DPIP. Foram incluídos na pesquisa 72 casos e 81 controles (voluntários saudáveis), ambos foram investigados para a exposição ambiental. A exposição aos fatores ambientais como pesticidas, herbicidas ou solventes orgânicos foi mais prevalente entre os pacientes com a doença de Parkinson de início Precoce.

$\mathrm{O}$ contato materno aos agrotóxicos foi relacionado à maior ocorrência de malformações congênitas e constatou 100\% a mais de casos de malformação congênita entre filhos de mães expostas aos agrotóxicos durante o período periconcepcional em relação às demais (OLIVEIRA et al., 2014).

Pignat et al. (2007) em estudo para verificar riscos de exposição ao agrotóxico, demonstraram que névoas de agrotóxicos provenientes da pulverização das lavouras lesaram hortas, plantas e folhagens de jardim, segundo relato obtido de moradores das cidades próximas a lavouras. Isso se denominou de "acidente rural ampliado", em que a magnitude e dimensão transcendem o ambiente de trabalho, colocando em ameaça a fauna, a flora e a saúde dos habitantes da cidade, como também podem causar danos imediatos (agudos) e/ ou tardios (crônicos) efeitos imponderáveis, surgindo tardiamente.

No estudo de Moreira et al. (2012), foi realizada análise da contaminação de águas superficiais e de chuva por agrotóxicos em duas cidades do Mato Grosso. Os autores relatam elevado consumo de herbicidas e fungicidas abordando um grande consumo de agrotóxicos (endosulfan e metamidofós), que são proibidos na Europa e Estados Unidos. Em um dos municípios, resíduos de agrotóxicos foram encontrados em $83 \%$ e na outra de $81 \%$ das amostras pesquisada, incluindo em poços que abastecem várias escolas da cidade.
Neste mesmo estudo se avaliou também a contaminação de organismo por exposição ambiental e os eventuais impactos dos agrotóxicos na reprodução e no desenvolvimento de anfíbios, observou-se a presença de organoclorados em 14 indivíduos de sapo-cururu, a partir de análise do plasma sanguíneo. Foram detectadas malformações apendiculares em cinco sapos-cururu, sendo essas comprovadas por exame visual e radiológica (MOREIRA et al., 2012).

A análise de indicador biológico, nas amostras de urina de 79 indivíduos residentes em um município de Mato Grosso, identificou a presença de resíduos de glifosato e piretroides, respectivamente $88 \%$ e $80 \%$ de amostras positivas, indicando que os trabalhadores e residentes das regiões rurais agrícolas, que estão em contato com a produção de soja, podem ter mais exposição ao glifosato enquanto os residentes da região urbana podem ser mais expostos aos piretroides, aplicado no controle e combate a vetores de doenças (BELO et al., 2012).

No estudo ecológico de Rigotto et al. (2013), os dados obtidos sugerem que nos municípios, que consomem mais agrotóxicos, ocorreram maior morbimortalidade por neoplasias, no qual podem estar sofrendo influências pelas mudanças produtivas, sociais e ambientais, relacionada à ampliação da tecnologia agrícola, aumentando o risco da comunidade rural.

É grande a problemática envolta na utilização dos agrotóxicos no Brasil e no Mundo, os danos cumulativos na saúde humana são remontados em diversas pesquisas, que elucidam diversas alterações sistemáticas, que acometem as populações expostas. Sendo necessária a discussão e implementação de políticas públicas efetivas na saúde do trabalhador, a fim de prevenir o risco do desenvolvimento de comorbidades associadas aos agrotóxicos.

\subsection{Exposição aos agrotóxicos, danos à saúde e ao ambiente}

A Organização Mundial da Saúde (OMS) estima que a cada ano em média 3 a 5 milhões de pessoas são contaminadas por agrotóxicos em todo o Mundo, esse número pode chegar a 25 milhões de trabalhadores rurais. No entanto, independentemente do número de indivíduos acometidos, é inegável a seriedade dos problemas, especialmente, nos países em desenvolvimento, que são responsáveis por aproximadamente $20 \%$ do consumo mundial dos agrotóxicos (PERES et al., 2003).

A exposição do indivíduo aos agrotóxicos vai desde a exposição ocupacional pelo contato direto e/ou indireto, dependendo de sua ocupação, bem como ambiental pela contaminação do ar, solo, alimentos, água (ABRASCO, 2012).

A inclusão destas inovações como o uso de agrotóxicos, de modo impróprio e indiscriminado, acarretou efeitos diretos e danosos sobre o ambiente e a saúde humana, a exposição a estas substâncias são um dos principais problemas de saúde pública (SANTOS, 2013).

Os dados de intoxicação humana e contaminação 
ambiental provocado pelo uso intensivo e generalizado de agrotóxicos são alarmantes, o uso seguro apresentado pelas indústrias pode mascarar tamanho perigo de seus produtos aos seres humanos (LONDRES, 2012).

Em função de sua toxicidade intrínseca, os agrotóxicos produzem efeitos lesivos à saúde humana, que variam de acordo com o princípio ativo do composto químico, a dose absorvida, a forma de exposição e as características individuais, em que o sujeito é exposto, ocasionando no indivíduo intoxicações que podem ser agudas, subagudas/ sobreagudas e crônicas (WHO, 2010).

As intoxicações agudas por agrotóxicos são as mais conhecidas e afetam, principalmente, as pessoas expostas em seu ambiente de trabalho (exposição ocupacional). Trazem efeitos como irritação da pele e olhos, coceira, cólicas, vômitos, diarreias, espasmos, dificuldades respiratórias, convulsões e morte (CASSAL et al., 2014; LONDRES, 2012).

Quanto à intoxicação aguda, os sintomas são percebidos logo após o contato com o composto químico, causada, geralmente, em decorrência de exposições por curto período, porém com concentrações muito elevadas, geralmente, os casos que são notificados são basicamente desse tipo. Intoxicação subaguda/sobreaguda ocorre quando a exposição é moderada ou pequena a produtos alta ou medianamente tóxicos. Os efeitos emergem em alguns dias ou semanas. As manifestações clínicas podem incluir cefaleia, fraqueza, malestar, dor de estômago, sonolência, etc. (LONDRES, 2012).

Já as intoxicações crônicas podem afetar toda a população, pois são decorrentes da exposição múltipla aos agrotóxicos, geralmente, em doses baixas. Os efeitos adversos decorrentes da exposição crônica aos agrotóxicos podem aparecer muito tempo após a exposição, dificultando a correlação com o agente (LONDRES, 2012).

Entre um conjunto de doenças investigadas e relacionadas às exposições crônicas se pode destacar o câncer e os distúrbios neurodegenerativos como, por exemplo, a doença de Alzheimer, esclerose múltipla, e a doença de Parkinson (SANTOS, 2013).

Os inseticidas organofosforados e carbamatos exercem suas ações biológicas, principalmente, por inibição das enzimas denominadas esterases, em especial, da acetilcolinesterase (AChE), que tem a ação de degradar o neurotransmissor acetilcolina (ACh). Com a AChE inibida, há acúmulo de ACh nos receptores muscarínicos, nicotínicos e no Sistema Nervoso Central (RELATÓRIO DE INTOXICAÇÕES AGUDAS POR AGROTÓXICOS, 2018).

A associação entre exposição aos pesticidas e a doença de Parkinson vem sendo remontada, em estudos recentes, como o realizado por Wang et al. (2014), em que se utilizou uma ferramenta de avaliação de exposição baseada no sistema de informações geográficas (GIS) para estimar a exposição ambiental a 36 organofosforados comumente usados de 19741999, os autores encontraram que a exposição ambiental a cada organofosforado avaliado separadamente aumentou o risco de desenvolver DP.

De acordo com o Protocolo de Avaliação da Intoxicações Crônicas por Agrotóxicos (Secretaria de Estado e Saúde do Paraná, 2013), as patologias relacionadas à intoxicação crônica por agrotóxicos são:

Neoplasias, como mieloma múltiplo e leucemias; anemia aplástica; transtornos mentais, como alterações cognitivas e episódios depressivos; doenças do sistema nervoso como distúrbios do movimento, polineuropatias e encefalopatia tóxica; oculares, como neurite óptica e distúrbios da visão e ainda auditivas, circulatórias, respiratórias, digestivas e dermatológicas.

Além das patologias apresentadas, estudos recentes apresentam uma relação entre a exposição direta aos agrotóxicos e o alto índice de suicídios em trabalhadores rurais. As substâncias podem afetar o sistema nervoso central, causando transtornos como ansiedade, irritabilidade, insônia ou sono conturbado e depressão, podendo levar o indivíduo ao suicídio (LONDRES, 2012; SANTOS, 2013).

Um dos maiores perigos representados pelos agrotóxicos diz respeito aos efeitos que esses podem provocar na saúde das pessoas, principalmente, daquelas que no campo ou na indústria, ficam expostas ao contato direto com os produtos (LONDRES, 2012).

\subsection{Impacto dos agrotóxicos na saúde}

Mesmo que alguns dos ingredientes ativos (IA) dos agrotóxicos possam ser classificados como medianamente ou pouco tóxicos, com base em seus efeitos agudos, não se pode perder de vista os efeitos crônicos que podem ocorrer meses, anos ou até décadas após a exposição. Estes efeitos se manifestam como neoplasias, más-formações congênitas, distúrbios endócrinos, neurológicos e mentais, entre outros (CARNEIRO, 2015). Além disso, a exposição a agrotóxicos leva também a ocorrência de asma, alergias e hipersensibilidade (VAN MAELE-FABRY et al., 2010). Tem-se também como efeitos dos agrotóxicos sobre a saúde humana os distúrbios psiquiátricos, neurológicos e neurites periféricas, surdez, doença de Parkinson etc. sendo que os mutagênicos, entre outros efeitos, induzem defeitos no DNA dos espermatozoides e óvulos (CONSEA, 2013).

\subsection{Agrotóxicos e câncer}

A exposição às substâncias químicas (agrotóxicos) em regiões de alta produção agrícola tem sido apontada como potenciais fatores causais dos cânceres, uma vez que a Agência Internacional de Pesquisa em Câncer classifica os agrotóxicos utilizados nas lavouras como potencialmente cancerígenos, por exemplo, o glifosato (PIGNATI et al., 2017).A exposição não intencional aos agrotóxicos pode ser extremamente perigosa para os seres humanos e outros organismos vivos (SARWAR, 2015). Estas substâncias também podem ser prejudiciais para pessoas expostas aos agrotóxicos através de ocupação ou atividades residênciais. 
O aumento da incidência de câncer, nos últimos 50 anos, pode ser atribuído não apenas ao envelhecimento da população, mas também à difusão de agentes cancerígenos, tanto no trabalho como no ambiente. Estudos epidemiológicos, de biologia molecular e toxicologia têm demonstrado que as exposições aos poluentes ambientais, incluindo osagrotóxicos, estão associados à crescente ocorrência de neoplasias (TEBOURBI; SAKLY; RHOUMA, 2011), indificando associações entre exposição ocupacional a agrotóxicos e atividade hormonal e o aumento de ocorrência de câncer de mama (KNOWER et al., 2014. BROPHY et al., 2012)some of which may not yet have been classified as such, are present in many occupational environments and could increase breast cancer risk. Prior research has identified associations with breast cancer and work in agricultural and industrial settings. The purpose of this study was to further characterize possible links between breast cancer risk and occupation, particularly in farming and manufacturing, as well as to examine the impacts of early agricultural exposures, and exposure effects that are specific to the endocrine receptor status of tumours. 1 nMethods: 1005 breast cancer cases referred by a regional cancer center and 1146 randomly-selected community controls provided detailed data including occupational and reproductive histories. All reported jobs were industry- and occupation-coded for the construction of cumulative exposure metrics representing likely exposure to carcinogens and endocrine disruptors. In a frequency-matched case-control design, exposure effects were estimated using conditional logistic regression. InResults: Across all sectors, women in jobs with potentially high exposures to carcinogens and endocrine disruptors had elevated breast cancer risk (OR = 1.42 ; $95 \%$ CI, 1.18-1.73, for 10 years exposure duration.

Alguns agrotóxicos são classificados como poluentes orgânicos resistentes (POPs). Uma vez absorvidos, os POPs são, principalmente, armazenados em tecido adiposo, inclusive, as mamas, nas quais podem ser liberados ou persistirem por longos períodos de tempo, que é o caso da mama (BRAUNER et al., 2012).

\subsection{Agrotóxico e câncer de mama}

O câncer da mama é o câncer mais frequentemente diagnosticado e a principal causa de morte por câncer em mulheres no Mundo (INCA, 2018). Fatores de risco estabelecidos como a idade, a história familiar, a genética, a reprodução e os fatores hormonais, incluindo história menstrual, utilização de contraceptivos orais, assim como comportamentos modificáveis, tais como: excesso de peso ou a obesidade, a utilização de estrogénio e progestina combinados, ausência de atividade física e o consumo de álcool ter sido associada a um risco aumentado de câncer da mama; no entanto, a etiologia de muitos casos de câncer de mama é desconhecida (BRASIL, 2016b). Como o câncer de mama é uma das causas predominantes de morte por câncer em mulheres em todo o Mundo, independentemente da etnia ou desenvolvimento econômico, há um crescente interesse em compreender as relações entre os fatores não-tradicionais de risco, tais como poluentes ambientais e câncer de mama (ELLSWORTH et al., 2018).

Os pesticidas têm recebido uma atenção especial em relação ao risco de câncer da mama, causa da capacidade de certos pesticidas em induzir tumores mamários em modelos animais ou causar efeitos in vitro relacionadas à etiologia do câncer da mama (JEMAL et al., 2014). Os aparentes efeitos de desregulação endócrina de alguns pesticidas suscitaram preocupações particulares em função da natureza hormonal de muitos fatores de risco conhecidos para o câncer de mama. No entanto, apesar de grande parte das pesquisas sobre pesticidas e câncer de mama estudaram a ação dos inseticidas organoclorados na ocorrência desses cânceres, várias outras classes de inseticidas também exibem tal atividade (ENGEL et al., 2017).

Importante destacar que nos ambientes de trabalho, em especial, indústria e agricultura, a utilização conjunta de vários componentes ativos dos agrotóxicos junto à exposição prolongada a essas substâncias são fatores que aumentam, ainda mais, a ocorrência de neoplasia (PERTILE et al., 2018).

\subsection{Morbimortalidade relacionada ao câncer de mama}

Dos 184 países incluídos na base de dados de uma instituição, que monitora a ocorrência de neoplasias no Mundo, esta neoplasia é a mais comum entre as mulheres, sendo a causa mais frequente de mortalidade em 101 países (ELLSWORTH et al., 2018; STEWART; WILD, 2014). Cerca de 600 mil novos casos por ano de neoplasias foram identificadas pelo Instituto Nacional do Câncer (INCA 2014), o câncer compreende a segunda causa de morte na população brasileira, ceifando a vida de 225 mil indivíduos anualmente. A estimativa é que até os 75 anos de idade, um em cada cinco brasileiros desenvolva algum tipo de câncer (JEMAL et al., 2014).

As taxas de incidência de câncer de mama continuam a aumentar, na grande maioria dos países, ao passo que suas taxas de mortalidade estão diminuindo em muitos países desenvolvidos e aumentando em países em desenvolvimento, sendo o grupo de doenças mais associado à exposição ambiental (AKRAM, et 1., 2017).

\subsubsection{Epidemiologia do Câncer de Mama}

Estudo na Alemanha informa que 37,2\% de todos os tumores invasivos são relacionados a fatores de risco não modificáveis (idade da menarca, idade da menopausa, paridade, doença benigna da mama e a história familiar de câncer da mama). Entre os fatores de risco modificáveis, o uso de terapia hormonal e inatividade física corresponderam a $19,4 \%$ e $12,8 \%$, respectivamente, aos tumores invasivos (STEWART; WILD, 2014).

A Organização Mundial da Saúde (OMS) relata que, de 1989 a 2006, a mortalidade por câncer de mama tem diminuído 
em alguns países, mas permaneceu estável ou até aumentou na Europa central. Os números variam de uma redução de 45\% na Islândia para um aumento de $17 \%$ na Romênia. Após a Islândia, as diminuições mais importantes foram encontradas na Inglaterra e no País de Gales (35\%), Escócia (30\%), Irlanda do Norte (29\%), Suécia (16\%), França (11\%) e Finlândia (12\%). Em contrapartida, a mortalidade continuou a aumentar na Grécia, na Estónia e na Letónia, não se verificando ainda qualquer redução na Bulgária ou na Lituânia (OMS, 2018).

Para o Brasil, estimam-se 59.700 casos novos $(56,33$ casos a cada 100 mil mulheres) de câncer de mama no biênio 2018-2019, junto às neoplasias de pele não melanoma, o mais frequente nas mulheres das Regiões Sul $(73,07 / 100$ mil), Sudeste (69,50/100 mil), Centro-Oeste (51,96/100 mil) e Nordeste (40,36/100 mil). Na Região Norte é o segundo tumor mais incidente (19,21/100 mil) (INCA, 2018).

O câncer de mama é de longe o câncer mais frequentemente diagnosticado e causa de morte por câncer entre as mulheres. Tendo havido 1,7 milhões de novos casos $(25 \%$ de todos os canceres nas mulheres) e 0,5 milhões de mortes de câncer ( $15 \%$ de todas as mortes por câncer em mulheres) em 2012. As taxas de incidência padronizadas por idade são mais altas na Europa Ocidental e menor na Ásia Oriental. As taxas de incidência tendem a ser elevadas em países que atingem os níveis mais elevados de desenvolvimento humano (STEWART; WILD, 2014).

\subsubsection{Agrotóxicos e Câncer de Mama}

Os agrotóxicos são agentes constituídos por uma grande variedade de compostos químicos ou biológicos, desenvolvidos para matar, exterminar, combater e repelir a vida. Normalmente, esses têm ação sobre a constituição física e a saúde do ser humano, além de se apresentarem como importantes contaminantes ambientais (PERES; MOREIRA; DUBOIS, 2003).

Tem sido detectada a presença dessas substâncias em amostras de sangue humano, no leite materno e resíduos presentes em alimentos consumidos pela população em geral, apontando a possibilidade de ocorrência de anomalias congênitas, de câncer, de doenças mentais, de disfunções na reprodução humana relacionadas ao uso de agrotóxicos (SOARES; PORTO, 2012).

Estudos demonstraram que, quando o agrotóxico é aplicado, contamina o ambiente e seu potencial tóxico afeta a saúde da população tanto urbana circunvizinha quanto a população rural gerando efeitos carcinogênicos, mutagênicos, teratogênicos, neuroendócrinos, dificuldades respiratórias, problemas de memória e de pele, depressão, entre outros (PIRES; CALDAS; RECENA, 2005).

Outros estudos atestaram que associações entre proximidade da residência a lavouras que usam agrotóxicos e a maior ocorrência de câncer de mama. Pesquisa realizada em Long Insland, Estados Unidos, demonstrou um aumento de mais de seis vezes do risco de câncer de mama em mulheres, que residiam próximo a lugares que anteriormente eram utilizadas para agricultura (O'LEARY et al., 2004). Outro estudo caso-controle de base hospitalar desenvolvido por He et al. (2017), realizado na China, demonstrou que os agrotóxicos organoclorados são fatores de risco para o câncer da mama, tendo em visto que estes compostos estavam presentes em cerca de $90 \%$ dos casos de câncer da mama do estudo.

\subsection{Agrotóxicos e doenças congênitas}

A literatura refere também vários estudos relacionados com a exposição ocupacional à pesticidas e a prevalência de doenças congênitas, relatando entre as malformações as fissuras orais (DUTRA, FERREIRA, 2017; GARCÍA et al., 1999; SILVA et al., 2011). Em um estudo de caso-controle, realizado na cidade de Petrolina, no Vale do São Francisco, com objetivo de avaliar a associação entre a exposição dos genitores aos agrotóxicos e o nascimento de filhos com doenças congênitas, houve maior exposição aos agrotóxicos durante a gestação em neonatos com defeitos congênitos (grupo caso) comparados ao grupo controle de crianças saudáveis. O risco foi aumentado quando pelo menos um dos genitores foi exposto ao agrotóxico (SILVA et al., 2011).

Oliveira et al. (2014), em uma pesquisa de caso-controle realizado com 219 nascidos vivos com malformação congênita e 862 nascidos vivos sadios, analisaram a associação entre o uso de agrotóxicos e as malformações congênitas em 8 municípios com maior exposição aos agrotóxicos em Mato Grosso. Os dados demonstram que a exposição materna aos agrotóxicos nos períodos pós-fecundação (primeiro trimestre gestacional) e no período total (soma dos três meses antes da fecundação e o primeiro trimestre gestacional) estão associadas às malformações congênitas dos municípios selecionados, sendo que as populações intensamente expostas aos agrotóxicos apresentaram maior risco de malformações fetais.

Dutra e Ferreira (2019), com objetivo de analisar a tendência de malformações congênitas associadas ao uso de agrotóxicos em microrregiões de Estados brasileiros com maiores produções agrícolas, constatou que nas microrregiões do Estado de Mato Grosso, os riscos de malformações no período de 2000 a 2016 foram de 1,26, ou seja, estatisticamente significativos.

A associação entre a exposição a pesticidas e malformações congênitas também foi investigada em um estudo de casocontrole realizado em crianças nascidas no Hospital Regional de Encarnacion, Itapúa-Paraguai, em que os fatores de risco associados com a malformação $(p<0,02)$ foram residir a menos de um quilômetro de campos, que fazem uso de herbicidas (BENÍTEZ-LEITE; MACCHIL, 2009).

De acordo com Leite et al. (2003), a exposição materna e ou paterna a poluentes ambientais teratogênicos no período periconcepcional, já colocam a criança em risco, pois podem afetar as células germinativas antes da concepção, produzindo danos genéticos, teratogênicos ou mutagênicos e, ainda, 
afetarem as células somáticas do embrião após a concepção.

Os pesticidas também estão entre os agentes ambientais mais frequentemente examinados para investigação das fissuras orofaciais. Esses representam uma vasta gama de substâncias químicas utilizadas como herbicidas, inseticidas, fungicidas, e fumegantes (ROMITTI et al., 2007).

Em pesquisa realizada por $\mathrm{Xu}$ et al. (2015), se procurou determinar a associação dos fatores ambientais com a etiologia da fissura labiopalatina não sindrômica em 200 casos e 327 controles recrutados de um hospital materno infantil na China. Foram encontrados como fatores que aumentaram o risco de fissuras orais a exposição a pesticidas e histórico familiar de fissura.

Suhl et al. (2018) em estudo de caso controle com o objetivo de examinar a exposição ocupacional de inseticidas, herbicidas e fungicidas em pais de crianças com fissuras, encontraram uma associação, significativamente, positiva entre a exposição ocupacional paterna a pesticidas. Essa associação foi mais observada entre pais, que foram potencialmente expostos aos inseticidas, fungicidas e herbicidas.

Romitti et al. (2007), em um estudo de meta-análise, visando avaliar os efeitos da exposição aos pesticidas sobre o risco de fissuras orofaciais, a exposição ocupacional materna aos pesticidas foi associada a um risco elevado e significante de fissuras. O mesmo foi encontrado em outros estudos, como Spinder et al. (2017), um estudo de caso controle na Holanda entre 1997 e 2013, em que também investigavam a associação entre a exposição ocupacional materna e fissuras, sendo que a exposição periconcepcional aos pesticidas e inseticidas foram fatores de risco associados ao risco aumentado de fenda do tipo palatina.

Hao et al. (2015), em um estudo de caso controle de base hospitalar, realizado na China, no período de 2009 a 2014, encontraram significativa relação entre a exposição ocupacional materna para determinados agentes tóxicos como pesticidas, solventes orgânicos, metais pesados, encontrando aumento de risco de fissuras labiopalatinas não sindrômicas.

$\mathrm{Na}$ Índia, um estudo caso-controle, ao longo de um período de cinco anos, também investigou o risco de exposição ao pesticida parental causar fissuras na região craniofacial. O estudo incluiu 179 casos de fissura e 200 controles, que mostraram ao comparar os grupos, que o grupo caso foi altamente exposto ao pesticida $(55,3 \%)$ sendo comparado a apenas 4,5\% nos controles. Esta diferença foi altamente significativa, mostrando o risco de exposição ao pesticida parental na ocorrência de fissuras. Os casos de fissura, que foram expostos aos pesticidas (86\%) eram da área rural e os controles, que não foram expostos (79 \%), eram da área urbana, encontrando também estatisticamente significância ( $p$ $<0,001$ ) (BETTY et al., 2019).

Já Yang et al. (2014), em estudo de caso controle realizado na Califórnia, avaliaram a exposição residencial aos pesticidas agrícolas, em áreas com alta taxa de usos de pesticidas. Os participantes foram expostos a 52 grupos de produtos químicos com base na proximidade residencial de 500 metros durante 1 mês antes e 2 meses após a data relatada da gravidez. Os resultados mostraram que 38,5\% das mães de crianças com fissura palatina e 37,9 das mães de criança com fissura labiopalatina tinham pesticidas aplicados próximo da residência, porém na análise estatística final, os estudos concluíram que não houve associação entre a exposição residencial aos herbicidas e fissuras orais.

Rappazzo et al. (2016), em estudo de caso controle, também avaliaram a exposição química baseada nas culturas, que estavam em um raio de 500 metros de residência materna, e seus resultados sugerem que vários defeitos de nascimento podem estar associados com a exposição aos pesticidas no início da gravidez, em que a fissura palatina e fissura labial com ou sem fenda palatina apresentaram ORs elevados para alguns níveis de exposição, porém nenhum padrão com níveis crescentes de exposição aos pesticidas foram detectados.

A exposição ambiental também foi relatada por Leite et al. (2003), que através de um estudo de caso controle realizado com crianças brasileiras do Rio de Janeiro, em que os autores associaram que a combinação do uso doméstico rotineiro de inseticidas e visitas frequentes de pulverização por órgãos públicos, controladores de vetores, foram estimativas significativas de risco de fissuras, principalmente, no primeiro trimestre gestacional. Neste estudo, também foi fator de risco a proximidade residencial de áreas industriais.

Shaw et al. (1999) relataram a exposição de mães aos pesticidas usados para jardinagem doméstica, e observaram o aumento de risco para maioria das anomalias estudadas, incluindo as fissuras orais.

\subsection{Agrotóxicos e depressão}

Em um estudo realizado por Salvi et al. (2003), com uma amostra de 37 trabalhadores do Sul do Brasil, envolvidos na agricultura familiar do tabaco, os mesmos foram avaliados quanto a exposição aos organofosforados e obtiveram como resultados 18 sujeitos (48\%), que tiveram um diagnóstico psiquiátrico na primeira entrevista realizada, 13 (35\%) tiveram diagnóstico de Transtorno de Ansiedade Generalizada e 8 (21\%) com diagnóstico de Episódio de Depressão Maior.

Em outro estudo, realizado no Nordeste do Colorado, cujo objetivo era avaliar a associação entre agrotóxicos e sintomas depressivos se obteve um resultado de odds ratio de 5,87 a um intervalo de confiança de $95 \%$, ou seja, exposição aos agrotóxicos em uma concentração suficientemente alta para causar sintomas de envenenamento autorrelatados, que foi associada aos sintomas de alta depressão, independentemente, de outros fatores de risco conhecidos para a depressão (STALLONES; BESSELER, 2002).

Faria et al. (1999) realizaram um estudo sobre a saúde mental dos agricultores da Serra Gaúcha, em que foram avaliados 1282 trabalhadores rurais de 446 estabelecimentos, destes 19\% haviam usado remédios psiquiátricos e 5\% haviam sido hospitalizados por problemas psiquiátricos 
em algum momento da vida. O tamanho da propriedade também apresentou relevância, propriedades com 26 a 50 hectares apresentaram um aumento de $46 \%$ na ocorrência de morbidade psiquiátrica. $\mathrm{O}$ fato de ter equipamentos, máquinas e automóvel no estabelecimento se associou a uma redução na prevalência dos transtornos psiquiátricos. Neste estudo, ainda, se mostrou que o uso de agrotóxicos não teve associação significativa com morbidade psiquiátrica menor.

Foi realizado uma pesquisa no Mississipi, cujo intuito era o de avaliar a depressão entre as vítimas do desastre do Metil Paration. Nessa pesquisa, os autores relataram que, em novembro de 1996, no Mississipi, a Agência de Proteção Ambiental (EPA), o Departamento de Estado de Saúde e a Agência de substâncias tóxicas descobriram que 1.800 moradias haviam sido contaminadas com Metil Paration (MP), entre essas, igrejas, creches e restaurantes. É ilegal usar o MP dentro de casa para matar insetos, apesar de sua eficácia, porque os níveis de toxicidade podem permanecer elevados, em muitos anos, em espaços fechados ou confinados. A exposição inicial ao MP, por inalação e absorção através da pele, pode ser seguida de sintomas durante 12 horas. Os efeitos neurotóxicos podem causar perda da coordenação, fadiga e até mesmo a morte.

Nessa pesquisa, os autores para avaliarem o nível de contaminação das residências classificaram em níveis, sendo nível I o maior grau de exposição e contaminação e o nível IV o menor nível de concentração e exposição. Para a realização da avaliação dos níveis, foi realizado o "teste de limpeza", em que pessoas usando roupas adequadas limpavam seis ou sete manchas no local no qual, provavelmente, foram pulverizadas com o veneno e, após isso, os esfregões foram examinados no laboratório. Para a variável depressão, foi utilizado um questionário, Escala de Depressão (CES-D). Como resultados foram obtidos que os afro-americanos apresentaram, significativamente, mais sintomas depressivos do que as pessoas brancas. Pessoas com menor renda também apresentaram mais sintomas depressivos (REHNER et al., 2000).

Freire e Koifman (2013) realizaram uma revisão sistemática sobre agrotóxicos, depressão e suicídio, avaliaram para isso os estudos no banco de dados do MEDLINE dos últimos anos (1995 e 2011). Segundo a pesquisa, essa diz que os estudos epidemiológicos relatam que a prevalência de depressão é maior nos países industrializados do que em países não desenvolvidos e se correlaciona, negativamente, com o status social. Quanto à depressão e ao suicídio, a literatura relata mais sobre a exposição aos organofosforados e em menor grau aos carbamatos, sendo que a depressão é um distúrbio frequentemente associado com a intoxicação aguda por organofosforados.

Nessa revisão sistemática, de 221 estudos publicados entre os anos correspondidos da pesquisa, apenas 22 foram inclusos na revisão, em função de atenderem ao critério da metodologia. Destes 22, dois estudos falaram sobre suicídio e depressão em relação à exposição aos pesticidas, que são os estudos de Parrón et al. (2011) e Wesseling et al. (2010). Os autores relataram que os agricultores, que viviam em áreas com maiores consumos com pesticidas estavam em maior risco para hospitalização por transtornos de humor, incluindo a depressão, quando comparados com a população de referência.

As pesquisas têm focado, principalmente, em trabalhadores expostos aos organofosforados (em função da plausibilidade biológica). A depressão tem múltiplos fatores de risco e dependem grandemente de suas características epidemiológicas e sociodemográficas. Sugere-se, cada vez mais, que a exposição a pesticidas é um fator de risco para depressão e suicídio. No entanto, a evidência epidemiológica é muito limitada, particularmente, em relação aos efeitos de exposições crônicas e de baixa dose, bem como uma relação causal, que ainda não foi estabelecida.

A intoxicação por organofosforados se apresenta responsável por até $80 \%$ das internações por intoxicação com agrotóxicos, sendo que as exposições, geralmente, ocorrem pelas vias dérmicas e pulmonares. A ação está relacionada pela inibição das enzimas colinesterásicas, que fazem acarretar um acúmulo de acetilcolina (ACh) extracelular e faz aumentar a ativação dos seus receptores nas sinapses colinérgicas. $\mathrm{O}$ sistema colinérgico estando hiperativado é uma das hipóteses para a neurobiologia da depressão (WRUCK, 2015).

\subsection{Agrotóxicos e desfechos adversos de gravidez}

De acordo com a Organização Mundial da Saúde (OMS), a anomalia congênita (AC) compreende qualquer malformação verificada no recém-nascido, intraútero ou após o nascimento, seja de natureza estrutural, funcional ou metabólica (OMS, 2016).

O Brasil, no período de 1990 a 2015, apresentou queda de $70,7 \%$ na taxa de mortalidade infantil $(47,1$ para 13,8 óbitos/1000 NV). Entretanto, as ACs passaram da quinta para a segunda posição entre as causas de morte, desde 1999 (IBGE, 2016).

Os termos 'defeitos, malformações ou anomalias congênitas' são utilizados para descrever distúrbios do desenvolvimento presentes no nascimento, podendo ser estruturais, funcionais, metabólicos, comportamentais ou hereditários (DUTRA; FERREIRA, 2019).

Apesar da maioria das MC não pode ser relacionada com uma causa específica, a exposição pré-natal aos agrotóxicos é sugerida como um fator que aumenta o risco de teratogenicidade e suscetibilidade da maioria dos sistemas fetais durante certos períodos de desenvolvimento (STILLERMAN et al., 2008).

Com relação aos defeitos congênitos, $40 \%$ a $45 \%$ das anomalias têm causas desconhecidas. A predisposição genética, como alterações cromossômicas e a mutação de genes, representam aproximadamente $28 \%$ das ocorrências; fatores ambientais representam aproximadamente 5 a $10 \%$, e a combinação entre influências genéticas e ambientais (herança 
multifatorial) representa 20\% a 25\% (SADLER, 2013).

Os agrotóxicos são utilizados para a produção de culturas e, em áreas urbanas, para o controle de doenças transmitidas por vetores, sendo potencialmente tóxicos para outros organismos, incluindo seres humanos (OMS, 2019). A exposição humana aos agrotóxicos pode ocorrer ambientalmente, por meio do ar, do consumo via resíduos em alimentos e água, bem como ocupacionalmente, durante ou após a aplicação interna/ externa (VAN DEN BERG et al., 2012).

A mortalidade proporcional por $\mathrm{MC}$ no Brasil vem aumentando progressivamente. Em 2014, as mortes por MC representaram a segunda principal causa de mortalidade infantil e a principal causa de mortalidade pós-neonatal (BRASIL, 2009).

No entanto, é importante ressaltar que poucos estudos analisam a incidência de $\mathrm{MC}$ e a exposição aos agrotóxicos específicos. Isso porque há enorme dificuldade metodológica na quantificação dessa exposição, uma vez que a população está sujeita aos múltiplos produtos químicos por meio de diferentes vias de contaminação e absorção (DUTRA; FERREIRA, 2019).

Um outro estudo brasileiro, do tipo caso-controle, avaliou a associação entre a exposição dos genitores aos agrotóxicos e o nascimento de crianças com MC no Vale do

São Francisco. A análise das variáveis relacionadas à exposição aos agrotóxicos mostrou um aumento do risco de ocorrência de MC, quando foram considerados: ambos os pais vivendo e trabalhando perto de lavouras; moradia próxima a lavouras; pai trabalhando na lavoura; pai aplicando produtos na lavoura e exposição aos agrotóxicos de pelo menos um dos progenitores. No entanto, não houve diferença estatística significativa entre os casos e os controles (SILVA et al., 2011).

No estudo desenvolvido por Oliveira et al. (2014), foram selecionados oito municípios com maior quantidade de agrotóxicos comercializados por área de cultivo na região de estudo (Mato Grosso), observando que a exposição materna ao agrotóxico foi significativamente associada com maior incidência de MC.

No contexto de contaminação por agrotóxicos, a população rural tende a ser a mais atingida. Agrotóxicos como a atrazina, o alacloro e o clorpirifós são classificados como DE, enquanto outros, como diuron e bifentrina, são classificados como substâncias tóxicas à reprodução (DUTRA; FERREIRA, 2019).

Além de possuírem classificações distintas, os agrotóxicos considerados teratogênicos também possuem diversos mecanismos de ação. Esses podem atravessar a placenta e serem absorvidos, sistemicamente, podem agir por meio da desregulação endócrina, da indução ao dano genético, causando defeitos nas células neuronais e o estresse oxidativo, sendo esses os mecanismos propostos como principais para a toxicidade desses produtos perante o desenvolvimento (VAN GELDER et al., 2010).

\section{Conclusão}

Conclui-se que a aplicação de agrotóxicos, de maneira adequada, segundo as normas e legislações vigentes para as plantações de culturas para fins comerciais de pequena a alta produtividade e, também, as culturas familiares pelos maiores riscos expostos as pessoas, que trabalham nesses cultivos e, principalmente, mulheres grávidas expostas ao uso direto ou indireto aos defensivos agrícolas, por terem maiores riscos de malformações congênita, assim como a população circunvizinha, que está exposta diretamente ou indiretamente ao plantio, ou consumidores do produto final.

Recomenda-se cuidado com os mananciais de água, que podem ser veículos de transposição de resíduos de agrotóxicos, os quais podem levar a maiores riscos de contaminação de mofo geral.

\section{Referências}

AGUIAR P.C. et al. Genetic and environmental findings in earlyonset Parkinson's disease Brazilian patients. Movement Dis., v.23, n.9, p.1228-1233, 2008. doi: 10.1002/mds.22032.

ALBUQUERQUE, P.C.C. et al. Health information systems and pesticide poisoning at Pernambuco. Rev. Bras. Epidemiol., v.18, n.3, p.666-678, 2015. doi: doi.org/10.1590/19805497201500030012 .

ANDRADE, T.O; GANIMI, R.N. Revolução verde e a apropriação capitalista. $C E S$ Rev., v.21, p.43-56, 2007. doi: 10.35977/0104-1096.cct2020.v37.26483.

ABRASCO - Associação Brasileira de Saúde Coletiva. Dossiê ABRASCO: um alerta sobre os impactos dos agrotóxicos na saúde. Parte 2 - Agrotóxicos, Saúde, Ambiente e Sustentabilidade. Rio de Janeiro: ABRASCO, 2012.

BEDOR, C.N.G. Estudo do potencial carcinogênico dos agrotóxicos empregados na fruticultura e sua implicação para a vigilância da saúde. Recife: Fiocruz, 2008.

BELO, M.S. et al. Uso de agrotóxicos na produção de soja do estado do Mato Grosso: um estudo preliminar de riscos ocupacionais e ambientais. Rev. Bras. Saúde Ocupac., v.37, n.125, p.7888, 2012. doi: 10.1590/S0303-76572012000100011.

BENÍTEZ-LEITE, S.; MACCHIL, M. L. Malformaciones congénitas asociadas a agrotóxicos. Arch. Pediatr. Uruguay., v.80, n.3, p.237-247, 2009. doi:10.4067/S0370-41062009000400010.

BETTY, A.J. et al. Non-genetic factors contribute to the incidence of non-syndromic clefts in the craniofacial region. Int. J. Anat. Res., v.7, n.32, p.6851-6858, 2019. doi: 10.16965/ijar.2019.241

BOCHNER, R. Sistema Nacional de Informações TóxicoFarmacológicas SINITOX e as intoxicações humanas por agrotóxicos no Brasil. Ciênc. Saúde Coletiva., v.12, n.1, p.73-89, 2007. doi: 10.1590/S1413-81232007000100012.

BOHNER, T.O.L.; ARAÚJO, L.E.B.; NISHIJIMA, T.O. Impacto ambiental do uso de agrotóxicos no meio ambiente e na saúde dos trabalhadores rurais. Rev. Eletr. Curso Direito, v.8, p.329-341, 2013. doi:10.5902/198136948280.

BOLOGNESI, C. Genotoxicity of pesticides: a review of human biomonitoring studies. Mutation Res. Rev. Mutation Res., v.543, n.3, p.251-272, 2003. doi: 10.1016/s1383-5742(03)00015-2.

BRASIL. Decreto ${ }^{\circ} 4.074$ de 04 de janeiro de 2002, regulamenta a Lei ${ }^{\circ} 7.802$, de 11 de julho de 1989. Diário Oficial da União, jan. 2002. 
BRASIL. Lei $\mathrm{n}^{\circ}$ 7.802, de 11 de julho de 1989 que dispõe sobre a pesquisa, a produção, a embalagem e rotulagem, o transporte, o armazenamento, a comercialização, a propaganda comercial, a utilização, a importação, a exportação, o destino final dos resíduos e embalagens, o registro, a classificação, o controle, a inspeção e a fiscalização de agrotóxicos, seus componentes e afins, e dá outras providências. In: Legislação federal de agrotóxicos e afins. Brasília (DF): Ministério da Agricultura e do Abastecimento; 1998. p. 15-53. Diário Oficial da União 1998; 08 jan.

BRASIL. Ministério da Saúde. Secretaria de Vigilância em Saúde. Departamento de Vigilância em Saúde Ambiental e Saúde do Trabalhador. Agrotóxicos na ótica do Sistema Único de Saúde Brasília: MS; 2018.

BRASIL. Relatório Nacional de Vigilância em Saúde de Populações Expostas a Agrotóxicos., v.1, p141, 2016.

BRÄUNER, E.V. et al. Predictors of adipose tissue concentrations of organochlorine pesticides in a general Danish population. $J$. Exp. Scie. Environ. Epidemiol., v.22, n.1, p.52-59, 2012.

BROPHY, J.T. et al. Breast cancer risk in relation to occupations with exposure to carcinogens and endocrine disruptors: a Canadian case-control study. Environ. Health., v.11, n.1, 2012. doi: 10.1186/1476-069X-11-87.

CÂMARA, H.F.; AUGUSTO, L.G.S. Riscos químicos e controle de pragas urbanas. In: AUGUSTO, L.G.S; CARNEIRO, R.M; MARTINS, P. H. (Org.). Abordagem ecossistêmica ensaios para o controle da dengue. Recife: Universitária da UFPE., 2005.

CARNEIRO, F.F. (Org.) Dossiê ABRASCO: um alerta sobre os impactos dos agrotóxicos na saúde. Rio de Janeiro: EPSJV, 2015.

CASSAL, V.B. et al. Agrotóxicos: uma revisão de suas consequências para a saúde pública. Rev. Eletr. Gestão, Educ. Tecnol. Amb., 2014.

CONSEA. Mesa de controvérsias sobre o impacto dos agrotóxicos na soberania e segurança alimentar e nutricional e no direito humano a alimentação adequada. Brasília: CONSEA, 2014.

DUTRA, L.S.; FERREIRA, A.P. Tendência de malformações congênitas e utilização de agrotóxicos em commodities: um estudo ecológico. Saúde em Debate, v. 43, p.390-405, 2019. doi: 10.1590/0103-1104201912108.

DUTRA, L.S; FERREIRA, A.F. Associação entre malformações congênitas e a utilização de agrotóxicos em Monoculturas no Paraná, Brasil. Saúde Debate; v.41, p.241-253, 2017. doi: 10.1590/0103-11042017S220.

FARIA, N.M.X. et al. Estudo transversal sobre saúde mental de agricultores da Serra Gaúcha (Brasil). Rev. Saúde Pública, v.33, p.391-400, 1999. doi: 10.1590/S0034-89101999000400011.

FARIA, N.M.X.; ROSA, J.A.R.; FACCHINI, L.A. Intoxicações por agrotóxicos entre trabalhadores rurais de fruticultura, Bento Gonçalves, RS. Rev. Saúde Pública, v.43, n.2, p.335-344, 2009. doi: 10.1590/S0034-89102009005000014.

FERREIRA FILHO, L.I.P. Estudo das alterações citogenômicas da medula óssea de trabalhadores rurais expostos a agrotóxicos Fortaleza: Universidade Federal do Ceará: Programa, 2013.

FREIRE, C.; KOIFMAN, S. Pesticides, depression and suicide: A systematic review of the epidemiological evidence. Int. J. Hyg. Environ. Health., p.445-460, 2013. doi: 10.1016/j. ijheh.2012.12.003.

FRIEDRICH, K. ABRASCO GT Agrotóxicos e Transgênicos da ABA. 2013.

HAO, Y. et al. Association of parental environmental exposures and supplementation intakewith Risk of Nonsyndromic Orofacial Clefts: A Case-Control Studyin Heilongjiang Province China.
Nutrients., v.7, p.7172-7184, 2015. doi: 10.3390/nu7095328.

HE, T.T. et al. Organochlorine pesticides accumulation and breast cancer: a hospital-based case-control study. Tumor Biol., v.39, n. 5, p.6, 2017. doi: 10.1177/1010428317699114.

IARC. IARC Monographs on the evaluation of carcinognic risks to humans, International Agency for Research on Cancer, Lyon: IARC, 2008.

INCA. Estimativa - 2018. Incidência de câncer no Brasil. Brasília: MS, 2018.

IBGE - Instituto Brasileiro de Geografia e Estatística. Indicadores de Desenvolvimento Sustentável: Brasil 2010. Rio de Janeiro: IBGE, 2010.

IBGE - Instituto Brasileiro de Geografia e Estatística. População: taxas de mortalidade infantil. 2016. Disponível em: <http:// brasilemsintese.ibge.gov.br/populacao/taxas-de-mortalidadeinfantil.html>. Acesso em: 24 ago. 2020.

IBAMA - Instituto Brasileiro do Meio Ambiente e dos Recursos Naturais Renováveis. Produtos agrotóxicos e afins comercializados em 2009 no Brasil: uma abordagem ambiental. Brasília: Ibama, 2010.

BAMA - Instituto Brasileiro do Meio Ambiente e dos Recursos Naturais Renováveis. Portaria Normativa Ibama $n^{\circ} 84$, de 15 de outubro de 1996. Disponível em:

$<$ https://servicos.ibama.gov.br/ctf/manual/html/Portaria_84. pdf $>$..

KNOWER, K.C. et al. Endocrine disruption of the epigenome: a breast cancer link. Endocrine Related Cancer., v. 21, n. 2, 2014.

LEITE, I.C.G.; PAUMGARTTEN, F.J.R.; KOIFMAN, S. Orofacial clefts in the newborn and environmental and occupational parental exposures: a case-control study in Rio de Janeiro, Brazil. Rev. Bras. Saúde Materno Infantil, v.3, n.4, p.401-409, 2003. doi: 10.1590/S1519-38292003000400005.

LONDRES, F. Agrotóxicos no Brasil: um guia para ação em defesa da vida. Rio de Janeiro: Rede Brasileira de Justiça Ambiental, 2012.

MATOS, A.K. Revolução verde, biotecnologia e tecnologias alternativas. Cad. FUCAMP., v.10, n.12, p.17, 2010.

MOREIRA, J.C. et al. Contaminação de águas superficiais e de chuva por agrotóxicos em uma região do estado do Mato Grosso. Ciênc. Saúde Coletiva., v.17, n.6, p.1557-1568, 2012. doi: 10.1590/S1413-81232012000600019.

O'LEARY, E.S. et al. Pesticide exposure and risk of breast cancer: a nested case-control study of residentially stable women living on Long Island. Environ. Res.., v.94, n.2, p.134-144, 2004. doi: 10.1016/j.envres.2003.08.001.

OLIVEIRA, N.P. Malformações congênitas e o uso de agrotóxicos em municípios de Mato Grosso, período de 2000 a 2009. Cuiabá: Universidade Federal de Mato Grosso, 2012.

OLIVEIRA, N.P. et al. Malformações congênitas em municípios de grande utilização de agrotóxicos em Mato Grosso, Brasil. Rev. Ciênc. Saúde Coletiva., v.19, n.10, 2014. doi: 10.1590/1413812320141910.08512014

OMS - Organização Mundial da Saúde. Metas globais de nutrição 2025: resumo da política sobre excesso de peso na infância. Genebra: OMS, 2014.

OPAS - Organização Pan-Americana da Saúde. Guias alimentares da criança brasileira menor de dois anos: bases científicas. Brasília: OPAS, 1997.

PERES, F.; MOREIRA, J.C.; DUBOIS, G.S. Agrotóxicos, saúde 
e ambiente: uma introdução ao tema. É veneno ou remédio? Rio de Janeiro: Fiocruz, 2003.

PIGNATI, W.A. et al. Distribuição espacial do uso de agrotóxicos no Brasil: uma ferramenta para a Vigilância em Saúde. Ciênc. Saúde Coletiva., v.22, n.10, p.3281-3293, 2017. doi: 10.1590/1413-812320172210.17742017.

PIGNATI, W.A.; MACHADO, J.M.H.; CABRAL, J.F. Acidente rural ampliado: o caso das "chuvas" de agrotóxicos sobre a cidade de Lucas do Rio Verde - MT. Ciênc. Saúde Coletiva., v.12, n.1, p.105-14, 2007.

PIRES, D.X.; CALDAS, E.D.; RECENA, M.C.P. Intoxicações provocadas por agrotóxicos de uso agrícola na microrregião de Dourados, Mato Grosso do Sul, Brasil, no período de 1992 a 2002. Cad. Saúde Pública., v.21, n.3, p.804-814, 2005. doi: 10.1590/ S0102-311X2005000300014.

PORTO, M.F.; SOARES, W.L. Modelo de desenvolvimento, agrotóxicos e saúde: um panorama da realidade agrícola brasileira e propostas para uma agenda de pesquisa inovadora. Rev. Bras. Saúde Ocupac., v.37, n.125, p.17-31, 2012. doi: 10.1590/ S0303-76572012000100004.

RAPPAZZO, K.M. et al. Maternal residential exposure to agricultural pesticides and birth defects in a 2003-2005 North Carolina Birth Cohort. Birth Defects Res., v.106, n.4, p.240-249, 2016. doi: $10.1002 /$ bdra. 23479 .

REHNER, T.A., et al. Depression among victims of South Mississipi's Methyl Parathion Disaster. Health Soc. Work, p.3340, 2000.

RIGOTTO, R.M. et al. Trends of chronic health effects associated to pesticide use in fruit farming regions in the state of Ceará, Brazil. Rev. Bras. Epidemiol., v.16, n.3, p.763-73, 2013. doi: 10.1590/S1415-790X2013000300019.

ROMITTI, P.A. et al. Meta-analysis: pesticides and orofacial clefts. Cleft Palate-Craniofac. J., v.44, n.4, p.358-365, 2007. doi: 10.1597/06-100.1.

SADLER, T.W. Langman embriologia médica. Rio de Janeiro: Guanabara Koogan, 2013.

SALVI, R.M. et al. Neuropsychiatric evaluation in subjects chronically exposed to organophosphate pesticides. Toxicol. Scie., v.72, p.267-271, 2003.

SANTOS, A.S.E. Consumo de agrotóxicos e doença de Parkinson no Brasil. Rio de Janeiro: Universidade Federal do Rio de Janeiro, 2013.

SARWAR, M. The dangers of pesticides associated with public health and preventing of the risks. Int. J. Bioinform. Biom. Eng., v.1, n.2, p.130-136, 2015.

Secretaria de Estado da Saúde do Paraná. Protocolo de Avaliações das Intoxicações Crônicas por Agrotóxicos. Curitiba, PR: Secretaria de Estado da Saúde; p.75, 2013.

SHAW, G.M. et al. Maternal pesticide exposure from multiple sources ans selected congenital anomalies. Epidemiology., v.10, n.1, p.60-66, 1999.
SILVA, S.R.G.; MARTINS, J.L.; SIEXAS, S.; et al. Defeitos congênitos e exposição a agrotóxicos no Vale do São Francisco. Rev. Bras. Ginecol. Obstet., v. 33, n. 1, p. 20-26, 2011.

SINDAG - Sindicato Nacional das Empresas de Aviação Agrícola. Estatísticas do setor. Disponível em: $<$ http://sindag.org. br/biblioteca-virtual/estatisticas-do-setor>.

SIQUEIRA, S.L.; KRUSE, M.H.L. Agrotóxicos e saúde humana: contribuição dos profissionais do campo da saúde. Rev. Esc. Enferm. USP., v. 42, n. 3, p. 1-7, 2008.

SOARES, W.L.; PORTO, M.F.S. Uso de agrotóxicos e impactos econômicos sobre a saúde. Rev. Saúde Pública., v.46, n. 2, p.209217, 2012. doi: 10.1590/S0034-89102012005000006.

SPINDER, N. et al. Maternal occupational exposure and oral clefts in offspring. Environ. Health., v.6, n. 83, 2017. doi: 10.1186/ s12940-017-0294-5.

STEWART, B.W.; WILD, C.P. World Cancer Report 2014. Lyon: International Agency for Research on Cancer/World Health Organization, 2014.

STILLERMAN, K.P. et al. Environmental exposures and adverse pregnancy outcomes: a review of the science. Reprod Sci., v.15, n.7, p.631-650, 2008. doi: 10.1177/1933719108322436.

TEBOURBI, O.; SAKLY, M.; RHOUMA, K.B. Molecular mechanisms of pesticide toxicity. InTech Open., p. 197-333, 2011.

TEIXEIRA, C.F. Exposição ocupacional aos insetos e seus efeitos na audição: a situação dos agentes de saúde pública que atuam me programas de controle de edemias vetoriais em Pernambuco. Recife: Fundação Oswaldo Cruz, 2000.

TYBUSH, J.S.; MARTINS, E.J. Revolução verde em ação versus revolução agroecológica em construção: os direitos da agrobiodiversidade e os caminhos para a sustentabilidade. Florianópolis: CONPEDI, p. 22, 2016.

VAN DEN BERG, H. et al. Global trends in the use of insecticides to control vector-borne diseases. Environ Health Perspect., v.120, n.4, p.577-582, 2012. doi: 10.1289/ehp.1104340.

VAN MAELE-FABRY, G. et al. Childhood leukaemia and parental occupational exposure to pesticides: a systematic review and meta-analysis. Cancer Causes Control., v.21, n.6, p.787-809, 2010. doi :10.1007/s10552-010-9516-7.

WANG, A. et al. The association between ambient exposure to organoph. The association between ambient exposure to organophosphates and Parkinson's disease risk. Occup. Environ. Med., v.71, n.4, p.275-281, 2014. doi: 10.1136/ oemed-2013-101394.

WHO - World Health Organization. Exposure to Highly Hazardous Pesticides: a Major Public Health Concern. Geneva: WHO, 2010.

YANG, S.; KRAMER, M.S. Preterm birth: temporal trends and socioeconomic inequalities. J. Pediatr., v.94, n.1, p.1-2, 2018. doi: 10.1016/j.jpedp.2017.06.002. 